\title{
Preliminary Inquiry for Mathematics Teaching of Fresh Undergraduates
}

\author{
Duan Wenxi \\ School of Applied Mathematics, Beijing Normal University Zhuhai, China \\ 236304613@qq.com
}

\begin{abstract}
Higher mathematics is a required course for the undergraduates of the engineering and economic management departments. However, they generally can't adapt to learning the mathematics. Therefore, the teachers should guide them to adapt to the learning environment of the university, improve the learning methods, to correct the wrong understanding of the university, to distinguish the difference for mathematics course between universities and high schools and correctly handle the relationship between remembering and understanding, grasp the characteristics of mathematics to improve the learning efficiency.
\end{abstract}

Index Terms - fresh undergraduates, higher mathematics, studying methods

\section{Introduction}

Higher mathematics is a basic course. It is the basic requirement and essential condition for the undergraduates to learn the subsequent courses and keep on the high-level study.

The fresh undergraduates generally aren't used to learning higher mathematics according to the sampling survey, even they feel difficult. [1] Only10 percent of the fresh students who are not in the mathematics department like to learn mathematics, 20 percent of them are interested in it, 30 percent of them remain neutral for learning mathematics, 30 percent of them have no interest in mathematics, 10 percent of them dislike it.

There are many reasons for the investigation to sum up: Higher mathematics is abstract. The students' basic knowledge is poor. However, the enthusiasm of them isn't high. After our observation and analysis for a long period, we think that the correct learning methods are the key reasons. Studying methods may affect the normal studies of the undergraduates and should have been drawn great attention to.

\section{Correct Mistaken Ideas to Meet the Higher}

Generally there are three kinds of wrong ideas among fresh undergraduates. Moreover, teachers should do their ideological work ahead of time.

1) Goodbye to the high school :It is generally thought that entering into the university is equal to say goodbye to the high school of hard learning and the study missions of youth are completed. It is easy stage to study and live natural and unrestrained life in the university.

Teachers should inform students that higher mathematics is rich and extensive in knowledge. It is larger than the amount of three courses in capacity of the middle school. However, the learning total of math, chemical and physics in the high school is less than that of utility in mathematics in the university a year. It is not easy for undergraduates to learn so much knowledge. Without the full mental preparation and paying double efforts than the middle school, they wouldn't have finished learning tasks of higher mathematics in the university.

2) Always the best: Some undergraduates think they were the top students in high schools, therefore, they also will be the excellent students in the university with a little effort and at least they will not be the students who lag behind in class. Actually otherwise, the undergraduates with good foundations and high IQs were the top students in high schools, but they are medium and even underachievers at the university. Therefore, we should educate them not to be too confident, not to lower their guard and become careless. Work harder, and they can achieve good results.

3) Long live the test scores of 60 points: Some undergraduates think that it is not important for the learning achievement in the university. It is OK to pass the exam. The teachers should remind them that the exam result is an important parameter to measure their learning performance. Moreover, it will be the basis of getting a degree certificate.

Therefore, teachers should guide them to correct the wrong understanding and learning attitude, to study hard and make continuous efforts and unremitting perseverance. They should pay double efforts in the university than in the middle school to finish the learning tasks in the university.

\section{Difference in Mathematics Courses between University and High School}

The teaching ways between university and middle school are generally in the following respects.

1)The class time is different: The time in each class at high school is 45 minutes. We should adjust the teaching course in a short period in order to cause the students' interest in listening to lectures. If the student doesn't understand the content, after class he can also learn himself. However, the teacher teaches only one subject in two classes in the university. If the undergraduate doesn't understand the content of the two classes, it is more difficult to learn themselves after class. So they should attend classes conscientiously in the classroom.

2) Teaching content is different: The teaching content and key points in each class at middle school are relatively small, only around these key points to explain more. Moreover, the problem of the content can be trained and solved in next class. However, the teaching content in every class in the university is more than that at high school. A series of definition, 
formulas, theorems and properties, inference will be launched in every class. Undergraduates are required to master the content in two classes each time.

3) The content joining is different: The relationship between the chapters and sections of the mathematics in the middle school is loose. Although the contents of the front haven't been mastered, those of the later can be learned well. However, the higher mathematics is a ring set of a ring. It can be learned step by step. The contents are closely intertwined. Only the content of the front have been mastered, the back content can be learned well. As a result, undergraduates are required not to cut school, master the teaching contents in a timely manner.

4)The teaching schedule is different: University teachers strictly carry out the teaching schedule according to the plans. After having finished the previous chapter, they quickly teach the next chapter. Therefore, they should guide undergraduates review and consolidate the learned content in time and be consistent with the teaching progress.

It is the transition period from childhood to adulthood that undergraduates are in the first and second grades in the university. Their willpower is not strong enough. Moreover, the time that they can concentrate on listening to the class is not long. Therefore, the teacher should pay attention to the characteristics of students, mobilize the atmosphere in the classroom at any time to avoid them being absent-minded.

\section{Correctly Handle the Relationship between Memorizing and Understanding}

Students feel difficult in learning math and their test results are not ideal. Most people attribute this phenomenon is due to no vivid explanation or unqualified teaching materials. However, the teacher said that the students didn't work hard and the parents didn't supervise their children. But the main reason is that the students don't memorize the key points of mathematics or realize the importance of the memory. Students think that mathematics is the discipline of understanding, not to be one of memorizing, which leads to no comprehension to mathematics.

We must know that memorizing is the sufficient condition of understanding. In turn, understanding promotes memorizing [2]. If students fail to remember the main points, then they don't understand all the relative contents. For example, the teacher told the definition and properties of the tiger, the mice and the cat, and talked about the story of "The cat catches mouse". This is one important theorem. At last the teacher asked the students how to prove that the tiger also catches the mice. The process to prove is because the tiger and the cat are the cat's category. The cat catches mouse, so the tiger also catches the mice. If students don't remember the definition and the theorem of cats, tigers and mice, they can not understand the whole proof process.

According to the survey, due to the thought that science is the discipline of understanding and the liberal arts is the subject of mechanical memorizing, the students spent a lot of time to recite English and their specialized courses. However, they rarely memorize the main points of mathematics after class.

They don't remember mathematics is equal to no foundation in the mathematics. So they can't understand the teacher's lectures without solid basic knowledge.

We asked the students to combine the memorizing with the understanding. What to remember is not a sample or a number, but to remember the four basics which named the basic definition, the basic conclusion, the basic formulas and the basic method. Only the undergraduates remember the four basics, can they understand and digest what they have learned and continue to learn the following contents.

\section{Think Highly of Five Key Links}

The four main aspects of higher mathematics are respectively taking a correct attitude, working hard, learning links, learning methods. Learning links refer to five learning courses which are preparing lessons before class, listening to lectures, digesting what they have learnt, doing their assignment and making the summary[3]. There are primary and secondary in the five processes, but they are very important. Learning methods are the learning skills adopted in completing the learning links. Learning method should be proper in order to save time, energy and have high efficiency. Therefore, the teachers should guide undergraduates to pay attention to their methods of studying, constantly sum up the learning experiences and strive to learn well.

1) Preparing lessons: The purpose of preparing lessons before class is to understand the next teaching content, pay attention to the difficult and key points of the next class. Then the undergraduates should concentrate on listening to the content what they can't understand in class. Whether they will prepare lessons or not depends on their own time and the efficiency of listening to lectures. If time is enough, you should prepare your lessons. When you are distracted and doze off in class or have other bad habits which lead to a bad result of listening to lectures, you must prepare your lessons in advance.

The teacher should advise undergraduates not to spend much time on the preparation, because teachers' explanations are easier than studying themselves and also will save a lot of time.

2) Attending classes. Attending a class is the most important learning link and must be attached great importance to. It is normal that undergraduates don't understand the content what the teacher has lectured in the class. The teacher should encourage them not to lose confidence if they can't understand the content. It will be completed by their pondering over and digestion after class.

In class, firstly teachers should ask students to seize the main and the secondary contradictions. The principal contradiction is to listen to the outlines and the points of the content in class. The big title of each part is the main outline. The main points are the definition, formulas, theorems and properties and inference conclusions of each part. The secondary 
contradictions refer to some auxiliary operation that the teacher taught.

Taking notes in the class when you attend lessons. There are three kinds of methods. (1)Write down all writing on the blackboard, this kind of method will cost a lot of energy and delay the time. (2) Record the main content of teachers' writing on the blackboard without some basic and simple derivation and operation process. It can be combined attending lessons with writing down the content. (3) Only list the outlines and points of the contents. This method can greatly improve the efficiency of listening to lectures, but you still have to review lessons after class according to the book. In short, these three methods have their own advantages and disadvantages, the undergraduates are free to choose.

3) Digesting what they have learnt: Digestion is reading class notes and textbook again after class in order to make clear the details which they did not understand in class and make a summary in time. The teachers should let the students listen to the new content after digesting the content of the last section. Moreover, it is possible that the content they didn't master in last class will be used in the next class.

4) Doing their assignment: Do exercises after class to solve the problem timely. Most exercises of the university are accordance with some definitions and conclusions that undergraduates need to remember. They are the most basic and as difficult as the problem of textbooks.

Through doing exercises, undergraduates can firmly memorize and deeply understand the key learned knowledge points. Only by doing the exercises, they can master what they didn't learn in class. However, through studying again and again, they can thoroughly understand the content.

The teachers should ask students to digest and summarize the learned contents and then do the exercises. If the students have remembered the key points, as long as they do a small amount of the related exercises, they can deeply understand the points. That is to get twice the result with half the effort. But if the students didn't remember the points, only did a lot of related exercises to master the key points, finally they can get half the result with twice the effort.

The teachers should encourage students to finish the homework independently, draw on each other' experiences and consult teachers more and more.

5) Making a summary: Make a summary for every class, each part and each chapter timely. When summing up, it is best to use charts and diagrams to summarize the outlines and points of the contents. Fill the definition, theorem and conclusion with concise, generalized words in charts and diagrams. Then the contents will be written in the charts with strict mathematical language. The summary method is the simplest and most clearly. Write the summary down on a piece of paper, you can read it every day more times and naturally remember well.

\section{Attach Great Importance to Work Schedule Time, Guarantee Studying Efficiency}

In order to ensure to learn well, teachers should supervise undergraduates to work and rest according to the schedule. They should have a good rest after continuous working. Taking a rest isn't wasting time. However, they should have a good rest to learn well[4]. The undergraduates should scientifically distribute the time among attending lessons, studying by themselves, having meals, entertainment and sleeping. Be sure not to stay up late or doze off at the first and second classes next day. Moreover, they should restrict the time allowed for surfing the Internet. Teachers should prevent undergraduates from being infatuated with computer games.

The undergraduates should make it a habit to take a nap in order to guarantee the learning efficiency in the afternoon. The time to take a nap is not long, but they must do it. This will mainly guarantee the good learning result in the afternoon.

The students should take breakfast every day. Otherwise, they must be very hungry in the third and fourth classes in the morning. They feel giddy and dizzy because the energy in the brain isn't enough. Therefore, they can't learn well and listen to lectures effectively.

\section{Undergraduates Should Improve Their Thinking Self- Cultivation}

It is the key stage to form a correct outlook on life in the university. Moreover, it is the important moment to raise the cognitive and distinguishing ability. The teacher should guide the undergraduates not only to learn the knowledge, but also to improve their ideological cultivation. However, the undergraduates are encouraged to learn from others' strong points to offset their weaknesses and to make a clear distinction between right and wrong.

The teachers should teach the undergraduates to study hard for the prosperity of the country. Moreover, they should be steady and earnest students on work and be industrious and thrifty, hard work and plain living. They should be sincere and simple, tolerant people and be united, not be selfish on common benefit. They should be diligent and obey public orders and follow teachers' advice, not be sluggish. They should be interested in all kinds of collective activities at spare time. In a word, the undergraduates should have comprehensively developed in morality, intelligence and physique and be excellent talents who have both ability and political integrity.

\section{References}

[1] Zhao Xiaodong, “Education Psychology",[1], Beijing, Peking University Press, 2006.

[2] Zhang Minghui, Shao Guanghua. "Memorizing and Understanding of Mathematics Learning". Journal of Qufu Normal University (Natural Science Edition) in 2005 the fourth period.

[3] Guo Qingshun "Modern Learning Theory and Technology". Guangdong, Zhongshan University Press. March in 2007.

[4] Liu Dianzhi, Tian Liangchen. "The Guide for Efficient Learning Strategy". Beijing, Science Press. January in 2011. 